\title{
The complex interactions of context availability, polysemy, word frequency, and orthographic variables during lexical processing
}

\author{
Caitlin A. Rice ${ }^{1,4} \cdot$ Natasha Tokowicz $^{1,2,3,4}$ (D) Scott H. Fraundorf ${ }^{1,3} \cdot$ Teljer L. Liburd $^{1,3,4}$
}

Published online: 18 April 2019

(C) The Psychonomic Society, Inc. 2019

\begin{abstract}
In this study we examined the interactions of context availability, polysemy, word frequency, and orthographic neighborhood variables during lexical processing. Context availability and polysemy interacted, in that words that were both lower in context availability and had fewer related senses were especially disadvantaged, as was originally reported by Tokowicz and Kroll (2007). Word frequency interacted with both polysemy and context availability, in that the effects of polysemy and context availability were stronger for lower-frequency words. Finally, orthographic neighborhood size and frequency both interacted with polysemy: the effect of polysemy was greater for words with smaller orthographic neighborhoods and a greater number of higherfrequency neighbors. These findings provide support for the context availability hypothesis (Schwanenflugel \& Shoben, 1983). Specifically, the feedback activation account (Hino \& Lupker, 1996) offers a mechanistic explanation of our findings that is rooted in feedback from semantic to orthographic representations.
\end{abstract}

Keywords Lexical access $\cdot$ Polysemy $\cdot$ Concreteness $\cdot$ Context availability $\cdot$ Orthographic neighborhood

A large proportion of words in many languages have multiple meanings that depend on the contexts in which they occur (e.g., Klein \& Murphy, 2001). Such semantically ambiguous words can be divided into two main types, based on meaning relatedness: homonyms and polysemes (for a review, see Eddington \& Tokowicz, 2015). Here we focus on polysemes, which are ambiguous words whose meanings are semantically related (e.g., FOOT can mean either $a$ body part or a unit of measure). Polysemes are of particular interest because they have an

Electronic supplementary material The online version of this article (https://doi.org/10.3758/s13421-019-00934-4) contains supplementary material, which is available to authorized users.

Natasha Tokowicz

Tokowicz@pitt.edu

1 Department of Psychology, University of Pittsburgh, Pittsburgh, PA, USA

2 Department of Linguistics, University of Pittsburgh, Pittsburgh, PA, USA

3 Learning Research and Development Center, University of Pittsburgh, Pittsburgh, PA, USA

4 Center for the Neural Basis of Cognition, University of Pittsburgh, Pittsburgh, PA, USA advantage in lexical decision relative to unambiguous words (Azuma \& van Orden, 1997); this advantage may arise because the multiple semantic representations of polysemes increase the amounts of semantic processing and semantic feedback that occur during lexical decision, relative to unambiguous words (e.g., Armstrong \& Plaut, 2008; Hino \& Lupker, 1996; Hino, Lupker, \& Pexman, 2002; Jager \& Cleland, 2016; Klepousniotou, 2002; Rodd, Gaskell, \& Marslen-Wilson, 2002).

In the present study, we used a lexical decision task to examine how polysemes are recognized, and further how polysemous word recognition may be affected by other lexical and semantic variables. The particular variables that we focused on are those that have been shown to interact with semantic ambiguity in the past-namely, concreteness/ context availability, orthographic neighborhood features, and word frequency. In doing so, we aimed to provide an inclusive account of the complex interactions between these lexical and semantic variables during lexical processing using linear mixed-effect modeling, and to improve on previous studies by examining polysemy as a continuous variable in terms of number of senses (NOS).

In what follows, we will first review the effects and interactions of the variables mentioned above that have been observed in the past to interact with polysemy (i.e., concreteness/ context availability, orthographic neighborhood features, and word frequency). First we examine in detail concreteness and 
context availability, in light of several decades of research dedicated to understanding concreteness effects and the fact that many studies have demonstrated concreteness effects in lexical decision (e.g., James, 1975).

\section{Concreteness in lexical processing}

Semantic ambiguity interacts with a variety of other variables during lexical processing, including concreteness (e.g., Tokowicz \& Kroll, 2007). The concreteness effect is a commonly investigated semantic effect that refers to the finding that concrete words, which refer to perceptible entities, are recognized more quickly than abstract words, which do not have easily perceptible referents. ${ }^{1}$ Although the concreteness effect is often thought of as ubiquitous in lexical decision (e.g., James, 1975; Schwanenflugel, Harnishfeger, \& Stowe, 1988), free recall (e.g., Paivio, 1971), sentence processing (e.g., Begg \& Paivio, 1969), and bilingual processing (e.g., van Hell \& de Groot, 1998a, 1998b), the literature in this area has described a complex and sometimes contradictory pattern of results, including numerous studies that have not shown a concreteness effect (e.g., Rubenstein, Garfield, \& Millikan, 1970; Samson \& Pillon, 2004; Schwanenflugel et al., 1988; Tokowicz \& Kroll, 2007; Tolentino \& Tokowicz, 2009) and a handful that have reported a reversal of the effect (e.g., Kousta, Vigliocco, Vinson, Andrews, \& Del Campo, 2011; Vigliocco et al., 2014) or a modulation of the effect by other variables (e.g., Kroll \& Merves, 1986; Tokowicz \& Kroll, 2007). Given that many studies have identified concreteness as being a critical modulator of lexical processing, it is important to first build a clear understanding of concreteness effects to better understand semantic ambiguity effects.

One hypothesis that might explain the inconsistent responses to concrete words in lexical-processing tasks is that apparent concreteness effects might really be effects of context availability. The context availability hypothesis (Schwanenflugel \& Shoben, 1983) attributes differences in the processing of concrete and abstract words to the ease of thinking of a context in which a word could occur. According to this hypothesis, it is easier to retrieve such contextual information for concrete than for abstract words on average, and as a result, concrete words are processed

\footnotetext{
${ }^{1}$ In some cases, researchers have examined a concept called imageability (the extent to which a word refers to an imageable entity) in place of concreteness (the extent to which a word refers to a perceptible entity; e.g., Paivio, 1968; Reilly \& Kean, 2007; van Hell \& de Groot, 1998b). Correlations between these two variables are generally high (e.g., $r=.87$, Campos \& González, 1992; $r=.78$, Gilhooly \& Logie, 1980; $r=.83$, Paivio, Yuille, \& Madigan, 1968), but see Richardson (1975) for a discussion of why they might not be perfectly interchangeable. In the present study, we chose to use concreteness because concreteness tends to have greater variance. The greater variance of concreteness makes it a better linear predictor, because the restricted range of imageability may attenuate correlations or lead to floor and ceiling effects (e.g., Kousta et al., 2011; Paivio, 1971).
}

more quickly than abstract words. This hypothesis predicts that when the ease of retrieving the context is equivalent, there should be no difference in response times in lexical decisions for abstract versus concrete words. Indeed, Schwanenflugel and Shoben demonstrated that the advantage in lexical decisions for concrete over abstract nouns disappeared when the words were embedded in supportive context sentences. Similarly, Schwanenflugel et al. (1988) found that the concreteness effect disappeared when context availability was controlled, and that context availability was a better predictor of lexical decision latencies than were concreteness, imageability, familiarity, or age of acquisition.

One aim of the present study was to test this context availability hypothesis, which predicts that context availability is a better predictor of word recognition than concreteness. If this hypothesis is correct, then a model of lexical decision response times with context availability as a predictor should be a better fit to the data than an otherwise identical model with concreteness instead of context availability. Previous studies have tested and found support for this hypothesis (e.g., Schwanenflugel et al., 1988; Schwanenflugel \& Shoben, 1983), but these studies did not control for a number of other psycholinguistic covariates now known to impact lexical processing, such as ambiguity and orthographic neighborhood variables. A novel contribution of the present study is reexamining the support for the context availability hypothesis using updated methods and controlling for previously uncontrolled variables.

\section{Interactions of concreteness with other variables}

The importance of concreteness/context availability to lexical processing raises the question of whether these variables qualify or alter semantic ambiguity effects. One of the first studies to examine this possibility was conducted by Tokowicz and Kroll (2007), who tested whether context availability and ambiguity interact during lexical decision. In their Experiment 3, native English speakers completed a lexical decision task with words that varied in concreteness, context availability, and NOS (albeit with some methodological issues noted below). Ambiguity and context availability interacted such that the effects of ambiguity were present only for words low in context availability (see also Rubenstein et al., 1970, who found a similar interaction for homophones). Interactions between ambiguity and concreteness/context availability have also been tested by Jager and Cleland (2016), who conducted two lexical decision experiments using only polysemes. In Experiment 1, they did not replicate the polysemy advantage in a set of concrete nouns, half of which had few (one to four) senses and half of which had many (six or more) senses. In Experiment 2, they developed a second word set comprising a 
mix of abstract nouns, verbs, adjectives, and adverbs that were matched on lexical features to the first set; half of these words had few senses (six or fewer), and half had many senses (seven or more). In this word set, they reported a significant polysemy advantage. The authors concluded that these results replicated the ambiguity and context availability interaction of Tokowicz and Kroll, because the polysemy advantage was present for abstract but not for concrete nouns.

However, these prior studies of concreteness/context availability effects on semantic ambiguity had several methodological weaknesses that we sought to address in the present study. For example, the Tokowicz and Kroll (2007) words included mostly polysemes, but the presence of 45 homonyms $(9.1 \%$ of items) makes it unclear whether the effects were due to number of meanings or NOS. Additionally, the study used the Kučera and Francis (1967) word frequency norms, which are a weaker predictor of lexical decision latencies than are other, more recently published sources (e.g., SUBTLEX $\mathrm{US}_{\mathrm{US}}$; Brysbaert \& New, 2009). Finally, the study used hierarchical linear regression models that only accounted for variance across items and not across participants.

The Jager and Cleland (2016) study also had methodological limitations. The study did not directly test for an interaction between polysemy and concreteness, but rather demonstrated a polysemy advantage in a set of abstract words but not in a separate set of concrete nouns. It is possible that these stimulus sets varied in other ways. For example, although stimuli were matched for number of orthographic neighbors, they were not matched for orthographic neighborhood frequency, which has direct effects on lexical decision latencies and interacts with concreteness (Samson \& Pillon, 2004). Second, the concrete words were only nouns, whereas the abstract words included a mix of parts of speech, which is problematic because ambiguous words with multiple noun meanings are recognized more slowly than ambiguous words with both noun and verb meanings (Armstrong \& Plaut, 2016; Mirman, Strauss, Dixon, \& Magnuson, 2010). Finally, Jager and Cleland used a noncontinuous measure of ambiguity, which is undesirable because dichotomizing a continuous variable reduces the amount of information available and may result in spurious results or a failure to find significant effects (e.g., Bissonnette, Ickes, Bernstein, \& Knowles, 1990; Cohen, 1983; Maxwell \& Delaney, 1993; Tokowicz \& Warren, 2008).

In the present study, we aimed to address some of the limitations of the Tokowicz and Kroll (2007) and Jager and Cleland (2016) studies. We directly tested whether an interaction between ambiguity and concreteness/context availability was present after excluding homonyms from the word set, obtaining a continuous measure of NOS, and controlling for part of speech. Additionally, we analyzed the results using linear mixed-effect models, which allowed us to account for both subject and item variance (Baayen, Davidson, \& Bates, 2008) and to use the full range of variability in NOS.

\section{Effects of orthographic neighborhood}

A second set of variables that affect semantic ambiguity are the orthographic neighborhood variables (Ferraro \& Hansen, 2002), which also interact with concreteness (Samson \& Pillon, 2004). Orthographic neighborhood size is the number of real words that can be derived from a target word by substituting one letter, while holding constant the number and position of the other letters (Coltheart, Davelaar, Jonasson, \& Besner, 1977). Orthographic neighborhood frequency is the number of higher-frequency neighbors that a target word has. Samson and Pillon found that words with larger orthographic neighborhoods are recognized more quickly, but words with a greater number of higherfrequency orthographic neighbors are recognized more slowly. In addition, orthographic neighborhood frequency (but not orthographic neighborhood size) interacted with concreteness, such that the typical concreteness effect emerged for words with one or more higher-frequency orthographic neighbors, but no concreteness effect was found for words with no higher-frequency orthographic neighbors (Samson \& Pillon, 2004). Samson and Pillon concluded that the presence of higher-frequency orthographic neighbors creates competition within the orthographic system, which allows for greater influence from the semantic system, thereby yielding concreteness effects. This view predicts that higher-frequency neighbors would allow concreteness effects to appear in lexical decision tasks, a claim we tested by adding an interaction term for concreteness/context availability with orthographic neighborhood frequency into our models. We included an additional interaction term of context availability and orthographic neighborhood size in order to examine all the potential ways in which context availability and orthographic neighborhood variables might interact.

Further evidence that semantic influences are larger when there is competition within the orthographic system has come from Ferraro and Hansen (2002), who reported a three-way interaction of orthographic neighborhood size, orthographic neighborhood frequency, and number of meanings. The effect of number of meanings decreased as orthographic neighborhood size increased, but only for words that had many (e.g., $M$ $=4.61$ ) higher-frequency neighbors. The research of Samson and Pillon (2004) and Ferraro and Hansen highlights the possibility of orthographic neighborhood variables interacting with both semantic ambiguity and concreteness, further motivating the present study.

\section{Lexical frequency}

One final variable that might interact with semantic ambiguity is lexical frequency, which has long been known to affect word recognition. The word frequency effect, the finding that 
higher-frequency words are recognized more quickly than lower-frequency words (Broadbent, 1967; Forster \& Chambers, 1973), is thought to stem from the fact that each encounter with a word strengthens memory traces and makes higher-frequency words easier to access in the future. Word frequency occupies a central place in several models of how people read and recognize words, including the dual-route model (Coltheart, Rastle, Perry, Langdon, \& Ziegler, 2001), the interactive activation model (McClelland \& Rumelhart, 1981; Rumelhart \& McClelland, 1982), and the EZ Reader model (Reichle, Pollatsek, Fisher, \& Rayner, 1998).

Of particular interest for the present study are numerous reports of semantic ambiguity interacting with word frequency; the general finding is that ambiguity advantages are strongest for low-frequency words. For example, Jastrzembski (1981) reported a significant interaction between number of meanings and frequency, such that unambiguous words were more affected by frequency than were words with multiple meanings. Specifically, low-frequency words benefited more from being ambiguous than did high-frequency words. Similarly, Pexman, Hino, and Lupker (2004, Exp. 1) conducted a lexical decision task with high- and low-frequency homonyms and unambiguous words; they reported an interaction between ambiguity and frequency such that low-frequency words showed an ambiguity advantage, whereas highfrequency words showed no effect of ambiguity. They explained this interaction using parallel distributed processing (PDP) models of word recognition, specifically those that incorporate semantic feedback (the spreading of activation from semantic back to lexical levels; e.g., Hino \& Lupker, 1996; Kawamoto, Farrar, \& Kello, 1994; Pexman et al., 2004; Plaut \& Shallice, 1993; Seidenberg \& McClelland, 1989). These models describe lexical processing using a dynamic and interactive network containing orthographic, phonological, and semantic levels. Initial activation begins at the orthographic and phonological levels and spreads in a feed-forward manner to semantic levels, and the semantic level in turn feeds activation backward to both the orthographic and phonological levels.

This framework can explain why ambiguity and word frequency have an interactive effect during word recognition. Higher-frequency words have greater initial resting activation at the orthographic level than do lower-frequency words. Therefore, lower-frequency words are at an initial disadvantage during lexical processing, but this disadvantage can be offset if they have more related meanings, because these words will receive greater semantic activation from their multiple semantic representations, and as activation spreads in a backward manner to the orthographic level, it will offset the weaker activity at the orthographic level.

Although ambiguity and frequency sometimes interact, they do not always. For example, Rubenstein et al. (1970), Hino and Lupker (1996, Exp. 1), and Hino, Lupker, Sears, and Ogawa (1998) have all failed to find an interaction of ambiguity and word frequency during lexical decision. One possible explanation for these discrepant results is that the studies that have failed to find an interaction of ambiguity and frequency did not distinguish between different types of ambiguity or used only homonyms (e.g., Pexman et al., 2004, made no distinction between polysemes and homonyms; Hino et al., 1998, used Japanese words with no distinction between polysemes and homonyms; and Hino \& Lupker, 1996, and Rubenstein et al., 1970, used homographs). To our knowledge, ours was the first study to examine the interaction of ambiguity and lexical frequency with words that have been carefully selected to be only polysemes, while retaining the continuous nature of frequency and ambiguity rather than dichotomizing these variables. We included an interaction term of NOS and word frequency in our models, to test for this effect.

Just as word frequency sometimes interacts with ambiguity, there have been several reports of word frequency interacting with concreteness, such that concreteness effects are strongest for low-frequency words. James (1975) reported that during lexical decision, the concreteness effect was apparent only for low- and intermediate-frequency words, whereas highfrequency concrete and abstract words were recognized equally quickly. Similarly, de Groot (1989, Exp. 4) reported an interaction of imageability (see note 1) and word frequency in lexical decision, such that the concreteness effect appeared only for low-frequency words, although this interaction was limited to the analysis by participants. On this basis, both de Groot and James suggested that the identification of highfrequency words can proceed without semantic information, whereas low-frequency words rely on semantic information to support rapid identification. ${ }^{2}$ We tested this idea in the present study by including an interaction of word frequency and context availability in our models.

\section{Present study}

We have reviewed a complicated body of literature examining various interactions between lexical and semantic variables during word recognition, and it appears that a number of inconsistent results might have been due to the widely varied definitions of semantic ambiguity that have been used to date. In the present study, we reexamined the pattern of interactions between lexical (orthographic neighborhood size, orthographic neighborhood frequency, and word frequency) and semantic (polysemy and concreteness/context availability) variables in a lexical decision task with a more refined definition of ambiguity:

\footnotetext{
${ }^{2}$ For further information about how the relative positioning of concrete and abstract blocks of words during lexical decision can impact the interaction of concreteness and word frequency, see Kroll and Merves (1986) and Tolentino and Tokowicz (2009).
} 
specifically, by testing a carefully selected set of words that are nonhomonymous polysemes (i.e., words that vary in NOS but have only one meaning). Furthermore, we offer a mechanistic account of these interactions in terms of feedback from semantic representations to orthographic representations (the feedback activation account; Hino \& Lupker, 1996).

To accomplish this, we asked whether there is an interaction between polysemy (measured in terms of NOS) and concreteness/context availability. We hypothesized that words that are low in concreteness/context availability would be particularly difficult to recognize due to their relatively impoverished semantic representations, and therefore they should particularly benefit from a greater NOS. Conversely, words that are low in both NOS and concreteness/context availability would be recognized most slowly. In other words, we predicted that the polysemy effect would be qualified by concreteness/context availability, such that the polysemy effect would be larger for words that were low in concreteness/ context availability. If we found such an interaction, which has been reported only twice before, this additional support could encourage theories of lexical processing to consider the role of semantic influences during word recognition.

We also tested the context availability hypothesis, which predicts significantly faster lexical decision times for words that are higher in context availability, even after controlling for other variables known to explain variance in lexical decision latencies. Furthermore, because this hypothesis proposes that apparent concreteness effects arise only because concreteness is partially confounded with context availability, a model with context availability should fit the data better than an otherwise identical model with concreteness instead of context availability.

Additionally, we also asked how polysemous word recognition is affected by other lexical variables: orthographic neighborhood and lexical frequency. On the basis of findings from Samson and Pillon (2004), we expected that orthographic neighborhood size and frequency would qualify both the NOS and concreteness/context availability effects. Specifically, we expected to find an interaction between orthographic neighborhood frequency and NOS, such that the effect of NOS would be most apparent for words that have higher-frequency neighbors. Similarly, we expected to find an interaction between orthographic neighborhood frequency and context availability, such that the effect of context availability would be most apparent for words that have higher-frequency neighbors. We made a similar set of predictions with regard to orthographic neighborhood size: We expected that it would interact with both NOS and context availability. Specifically, the effects of NOS and context availability would be more apparent for words with a lower orthographic neighborhood size. On the basis of a report by Ferraro and Hansen (2002), we also expected a higher-order interaction of orthographic neighborhood frequency, orthographic neighborhood size, and NOS.
Finally, on the basis of several reports of interactions between ambiguity and word frequency (e.g., Jastrzembski, 1981; Pexman et al., 2004), we predicted that the effect of NOS would be larger for low-frequency words. Similarly, on the basis of previous reports of an interaction between concreteness and word frequency (e.g., de Groot, 1989; James, 1975; Kroll \& Merves, 1986), we hypothesized that the concreteness/context availability effect would be larger for low-frequency words.

The common thread that unites all these predictions is the proposal that the effects of orthographic and semantic variables interact during lexical processing, and furthermore that the effects of semantic variables become most pronounced when orthographic information is impoverished or conflicting (such that competition arises within the orthographic system). If our predictions were confirmed, this should encourage researchers to further investigate how impoverished lexical activation may lead to greater semantic influence during lexical processing, and conversely how sparse semantic information might lead to greater reliance on lexical variables.

\section{Method}

\section{Participants}

The participants were 102 monolingual English speakers recruited from the University of Pittsburgh Department of Psychology participant pool, who were given credit toward a class requirement for their participation. Data from 20 of these participants were excluded: 17 due to low accuracy, two due to equipment malfunctions during testing, and one due to missing data. The data from 82 participants remained for the analysis. All participants were 18 years of age or older, were right-handed, and had normal or corrected-to-normal vision.

\section{Stimuli}

The stimuli were a subset of 497 words from the stimulus lists used by Tokowicz and Kroll (2007) and 497 pseudowords matched to the words on word length, number of orthographic neighbors, and bigram frequency (see Table 1). Pseudowords were constructed by querying the eLexicon database (Balota et al., 2007) for nonwords that were matched to the Tokowicz and Kroll real words in length, orthographic neighborhood size, and bigram frequency. This method yielded Englishlike pseudowords that were pronounceable and had no illegal bigrams.

Forty-five of the original 497 words (9.1\% of items) were included in the experiment but were later removed from the analyses because data extracted from WordNet (Miller, 1995) revealed that they had more than one meaning (i.e., were 
Table 1 Stimulus properties

\begin{tabular}{|c|c|c|c|c|}
\hline & \multicolumn{2}{|l|}{ Words } & \multicolumn{2}{|c|}{ Pseudowords } \\
\hline & Mean & $S D$ & Mean & $S D$ \\
\hline Length (number of letters) & 5.87 & 1.67 & 5.79 & 1.68 \\
\hline Number of senses $(\mathrm{NOS})^{\mathrm{a}}$ & 5.19 & 3.90 & - & - \\
\hline Orthographic neighborhood frequency ${ }^{\mathrm{b}}$ & 0.69 & 1.37 & - & - \\
\hline Orthographic neighborhood size ${ }^{\mathrm{b}}$ & 3.06 & 4.17 & 3.27 & 4.42 \\
\hline Concreteness $^{\mathrm{c}}$ & 4.53 & 1.77 & - & - \\
\hline Context availability ${ }^{\mathrm{d}}$ & 5.80 & 0.69 & - & - \\
\hline Word frequency ${ }^{\mathrm{e}}$ & 3.54 & 0.41 & - & - \\
\hline
\end{tabular}

${ }^{\mathrm{a}}$ WordNet (Miller, 1995); ${ }^{\mathrm{b}}$ eLexicon project (Balota et al., 2007); ${ }^{\mathrm{c}}$ Normative ratings from 71 raters; ${ }^{\mathrm{d}}$ Normative ratings from additional 70 raters; ${ }^{\mathrm{e}}$ Zipf-scaled SUBTLEX-US word frequency (Brysbaert \& New, 2009).

homonyms). The remaining 452 words had exactly one meaning, but varied in NOS.

Numbers of senses were extracted from WordNet and ranged from 1 to $35(M=5.26, S D=3.91)$. To check the reliability of these data, the NOS data from WordNet were compared to the NOS data from the Wordsmyth Online Dictionary (collected by the eDom project; Armstrong, Tokowicz, \& Plaut, 2012); the two were highly correlated ( $r$ $=.98$ ) for this sample. An item-level comparison revealed that discrepancies in NOS between the two databases were never greater than two senses, except for one word with a discrepancy of six senses (respect). This item was removed, leaving a total of 451 words for the analyses.

To examine the effects of word frequency, we used a Zipfscaled measure of word frequency, which has the advantage of allowing for frequencies lower than one per million (van Heuven, Mandera, Keuleers, \& Brysbaert, 2014). To obtain this, we extracted the SUBTL word frequency norms from the SUBTLEX $_{\text {US }}$ corpus (Brysbaert \& New, 2009). We then applied Zipf scaling to the SUBTL word frequency counts (e.g., van Heuven et al., 2014), but edited the denominator of the Zipf equation to reflect the size of the SUBTLEX $X_{U S}$ corpus instead of the SUBTLEX $\mathrm{UK}_{\mathrm{UK}}$ corpus.

To measure the concreteness and context availability of the real words, normative ratings were collected from undergraduate students at the University of Pittsburgh; one group $(N=$ $98)$ rated context availability, and another $(N=98)$ rated concreteness. None of these participants had completed the main experiment. The instructions for context availability ratings were adapted from Schwanenflugel and Stowe (1988): Participants were instructed to rate on a 7-point Likert-type scale how easy (1) or hard (7) it was for them to think of a context for a given word. Instructions for concreteness ratings were adapted from Spreen and Shulz (1966): Participants were instructed to rate the words on a 7-point Likert-type scale from 1 (least concrete) to 7 (most concrete). For both the concreteness and context availability ratings, participants were instructed to rate all items using the full range of the scale. Responses from participants who did not use the full scale (i.e., at least one "1" and one "7") were excluded. Of the 98 respondents who rated concreteness, 27 were excluded ( 15 for missing data, nine for a language background other than native English speaker, and three for not using the full rating scale). Of the 98 respondents who rated context availability, 28 were excluded (four for missing data, four for a language background other than native English speaker, 16 for not using the full rating scale, and four for having already responded to the survey). Thus, concreteness ratings were computed from a final set of 71 participants, and context availability ratings were computed from a final set of 70 participants.

The average concreteness and context availability ratings were calculated for each real word using the normative ratings (see the supplementary material). Orthographic neighborhood size and orthographic neighborhood frequency were extracted from the eLexicon project (Balota et al., 2007; see Table 1). Table 2 presents example stimuli.

\section{Design and procedure}

The participants in the main experiment completed a computerized lexical decision task in which they were presented with a word or pseudoword and responded by pressing a key with their dominant (right) hand for "word," or another key with their nondominant (left) hand for "nonword." Each trial began with a fixation cross with a duration that varied randomly between 170 and $230 \mathrm{~ms}$. Next, a target word appeared on the screen until the participant had responded or 3,000 ms had elapsed, whichever came first. All participants viewed all 497 words and 497 pseudowords, which were presented in randomized blocks of 100 trials with a self-timed break between blocks. All trials were presented on a PC running E-Prime version 2.0 (Psychology Software Tools, Sharpsburg, PA), and response time (in milliseconds) and accuracy were collected. Following the lexical decision task, participants completed a language history questionnaire (Tokowicz, Michael, \& Kroll, 2004) to confirm their language background.

\section{Results}

\section{Analysis approach}

Response times were analyzed using linear mixed-effect regression models (Baayen et al., 2008) to account for random effects of both subjects and items, while examining the experimental fixed effects that were of theoretical interest in the study. Ninety-five-percent confidence intervals are reported for all fixed effects. All analyses were conducted in R using 
Table 2 Example stimuli

\begin{tabular}{lll}
\hline & Low NOS & High NOS \\
\hline Low context availability & temerity, stapler, tranquility, pamphlet & policeman, childhood, ambulance, wheat \\
High context availability & mind, square, water, honor & break, train, space, baby \\
\hline
\end{tabular}

version 1.1.14 of the lme4 package (Bates, Maechler, Bolker, \& Walker, 2014) and version 2.0.36 of the lmerTest package (Kuznetsova, Brockhoff, \& Christensen, 2017) to assess significance.

\section{Data processing}

Our interest was in how the lexical and semantic features of real words affect processing, so the pseudoword fillers were removed before conducting the regression analyses. In addition, 1,302 incorrect responses to real words were excluded ( $<$ $4 \%$ of the trials). Data were excluded from participants with less than $90 \%$ accuracy on lexical decisions for word and pseudoword trials combined (following Tokowicz \& Kroll, 2007), which resulted in the removal of 17 participants $(17 \%$ of the original sample); pseudoword accuracy was below $90 \%$ for all 17 of the excluded participants, whereas word accuracy was below $90 \%$ for only two of these 17 participants (87\% and $89 \%$ ). Responses faster than $200 \mathrm{~ms}$ were considered spurious and were therefore excluded, which resulted in the removal of 15 additional trials $(<1 \%$ of the correct word trials). Trials with response times 2.5 standard deviations or greater above or below a participant's mean response time for real words were excluded as outliers and treated as missing values, which resulted in the removal of 1,119 trials ( $3 \%$ of the correct word trials). Aside from these exclusions, there were no other missing data.

After exclusions, participants' mean accuracy ranged from $93 \%$ to $99 \%(M=97 \%)$; that is, all of the participants we included answered nearly all trials correctly. Because of this near-ceiling accuracy, we focused our analyses on the response times for correct trials.

In all analyses, the predictor variables of previous-trial response time, word length, concreteness, context availability, word frequency, and NOS were mean-centered in order to eliminate nonessential multicollinearity (Jaeger, 2010). Previous-trial response time was scaled to match the other variables by dividing by 1,000 .

As we noted in the introduction, a goal of the present research was to disentangle the effects of concreteness and context availability, two variables that are highly correlated ( $r=$ .76; see Table 3 ). Before beginning our analyses, we wanted to make sure we could clearly test the effects of each of these as independent predictors; therefore, we assessed the risk of multicollinearity arising from using these related predictors in the same model. We first examined the condition number, a test of the overall amount of collinearity in a model (Baayen, 2008). The condition number indicated that there was medium collinearity $(\kappa=20.59)$, although this value falls below the threshold for potentially harmful collinearity ( $\kappa=30$; Baayen, 2008). We then examined the variance inflation factor (VIF), a measure of how much the individual variables in a model are affected by collinearity (Frank, 2011). A VIF value over 5.00 is potentially problematic, and we observed values of 6.12 for context availability and 5.56 for concreteness. Therefore, we concluded that including both concreteness and context availability in the same model would yield potentially harmful multicollinearity, which could result in overfitting of the model or inaccurate and unstable estimates of predictors. To avoid this and to assess the independent effects of concreteness and context availability, we fit and present two models, one in which context availability but not concreteness was entered as a predictor, and a second in which the reverse was true. We then present model comparisons in order to assess whether concreteness or context availability was a better independent predictor of lexical decision latencies.

\section{Word status effects}

The data for words and nonwords were compared using $t$ tests across both participants $\left(t_{1}\right)$ and items $\left(t_{2}\right)$ to examine word status effects on response time and accuracy. Consistent with past reports, words were responded to significantly more quickly $(585.02$ vs. $682.55 \mathrm{~ms}), t_{1}(81)=14.74, p<.001 ; t_{2}(946)=$ $28.71, p<.001$, and more accurately $(96.63 \%$ vs. $93.13 \%$ correct), $t_{1}(82)=6.32, p<.001 ; t_{2}(946)=6.70, p<.001$, than nonwords.

Table 3 Correlations of variables of theoretical interest

\begin{tabular}{llllll}
\hline & ONF & ONS & Concreteness & CA & NOS \\
\hline ONS & $.71^{* *}$ & & & & \\
Concreteness & $.17^{* *}$ & $.18^{* *}$ & & & \\
CA & $.13^{* *}$ & $.24^{* *}$ & $.76^{* *}$ & & \\
NOS & .03 & $.27^{* *}$ & .01 & $.12^{* *}$ & \\
WF & .08 & $.14^{* *}$ & .09 & $.35^{* *}$ & $.19^{* *}$ \\
\hline
\end{tabular}

$\mathrm{CA}=$ context availability, $\mathrm{NOS}=$ number of senses, $\mathrm{ONF}=$ orthographic neighborhood frequency, ONS = orthographic neighborhood size, $\mathrm{WF}=$ Zipf-scaled SUBTLEX $\mathrm{US}_{\mathrm{S}}$ word frequency. ${ }^{* *}$ Correlation is significant at the .01 level. 


\section{Real-word trials}

After verifying the presence of the expected real-word advantage, we removed the nonword trials and constructed two linear mixed-effect models: Model 1 with context availability as a key variable, and Model 2 with concreteness replacing context availability. In Model 1, the following interactions were of theoretical interest: word frequency by context availability, word frequency by NOS, context availability by NOS, context availability by orthographic neighborhood size, context availability by orthographic neighborhood frequency, NOS by orthographic neighborhood size, and NOS by orthographic neighborhood frequency. ${ }^{3}$ The fixed effects of previous-trial reaction time, previous-trial accuracy, and word length were included, to control for variables known to be associated with word recognition. Model 2 was identical to Model 1, with the exception that context availability was replaced by concreteness. In both models, the dependent variable was lexical decision latency (in milliseconds).

For both models, we specified the maximal random-effect structure justified by our experimental design, using a theorydriven approach that maximized the chance that our results would generalize to new subjects and items (e.g., Barr, Levy, Scheepers, \& Tily, 2013). We began with the assumption that we would expect different subjects and items to have different lexical decision latencies, and therefore included random intercepts for subjects and items. Furthermore, we hypothesized that subjects (in both our sample and the general population) might be differentially sensitive to all of the fixed effects of theoretical interest. Therefore, we included bysubject random slopes for all interactions. We did not specify random effects for the control variables (see Barr et al., 2013).

The model equations and results for Models 1 and 2 are presented in Tables 4 and 5, respectively, and estimates of the random effects are presented in Tables 6 and 7. We compared Model 1 to Model 2 using the Bayesian information criterion (BIC) for nonnested models. BIC estimates the information lost from reducing a presumed "true" underlying model to the existing model. A lower BIC value indicates that less information is lost, and thus shows which model is a better fit for the dataset. We found that Model 1 (context availability; BIC $=437,032$ ) was a better fit for the data than Model 2 (concreteness, $\mathrm{BIC}=437,173)$. Therefore, in the following section, we will discuss only Model 1 in detail.

The model results reveal a complex pattern of interactive effects. We hypothesized seven significant interactions: word frequency and context availability, word frequency and NOS, context availability and NOS, context availability and orthographic neighborhood size, context availability and orthographic neighborhood frequency, NOS and orthographic

\footnotetext{
${ }^{3}$ We thank an anonymous reviewer for suggesting analyzing the final two interactions.
}

neighborhood size, and NOS and orthographic neighborhood frequency. In fact, only five of the seven interactions proved to be significant predictors of lexical decision latencies. The interactions of context availability and the two orthographic variables failed to reach significance. The five significant interactions were probed using the regression equation from Model 1 to generate estimated lexical decision latencies at one standard deviation above and below the mean of each variable (e.g., Aiken \& West, 1991; Hughes, 2018).

First, the significant interaction of word frequency and context availability demonstrated that the effect of context availability was greater for lower- than for higher-frequency words, $b=33.30, S E=4.80, t=6.94$ (see Fig. 1). Second, the interaction of word frequency and NOS, $b=5.99, S E=1.49, t=$ 4.01 (see Fig. 2) shows that the effect of NOS was greater for lower- than for higher-frequency words.

Third, context availability and NOS interacted, $b=3.80$, $S E=1.06, t=3.59$ (see Fig. 3), such that words that are lower in context availability and lower in NOS are especially disadvantaged. Fourth, we found a significant interaction of NOS and orthographic neighborhood size, $b=-0.21, S E=0.07, t=$ -2.80 (see Fig. 4), such that the effect of NOS was greater for words that have more orthographic neighbors. Fifth, there was a significant interaction of NOS and orthographic neighborhood frequency, $b=-0.97, S E=0.42, t=-2.29$ (see Fig. 5), such that the effect of NOS was only present for words that have higher-frequency neighbors.

Finally, we tested for the hypothesized three-way interaction of orthographic neighborhood size, orthographic neighborhood frequency, and NOS. To conduct this test, we began with Model 1 and added a three-way interaction term for orthographic neighborhood size by orthographic neighborhood frequency by NOS to the model as a fixed effect. This higherorder interaction term failed to reach significance, so it was removed from the model. We repeated the same procedure with Model 2, and this interaction term failed to reach significance as well.

\section{Replication using British Lexicon Project lexical decision data}

Despite the large dataset collected in the present study, the model we tested was complex, and for this reason we conducted supplementary analyses to investigate whether the results we report above were replicated in other lexical decision databases. ${ }^{4}$ We identified three potentially suitable lexical decision datasets for this purpose: the original Tokowicz and Kroll (2007) dataset, the English Lexicon Project (ELP; Balota et al., 2007), and the British Lexicon Project (BLP; Keuleers, Lacey, Rastle, \& Brysbaert, 2012). We attempted to fit Model 1 to the original Tokowicz and Kroll (2007)

\footnotetext{
${ }^{4}$ We also thank an anonymous reviewer for this suggestion.
} 
Table 4 Fixed-effects estimates for Model 1

\begin{tabular}{|c|c|c|c|c|c|c|}
\hline & \multirow[t]{2}{*}{ Estimate } & \multirow[t]{2}{*}{$S E$} & \multicolumn{2}{|l|}{$95 \% \mathrm{CI}$} & \multirow[t]{2}{*}{$t$} & \multirow[t]{2}{*}{ Significance } \\
\hline & & & Lower Bound & Upper Bound & & \\
\hline Intercept & 645.97 & 7.94 & 630.40 & 661.53 & 81.35 & $* * *$ \\
\hline Previous-trial RT & 79.62 & 2.86 & 74.02 & 85.21 & 27.87 & $* * *$ \\
\hline Previous-trial accuracy & -74.07 & 3.58 & -81.09 & -67.05 & -20.68 & $* * *$ \\
\hline Length & 7.20 & 1.13 & 4.98 & 9.41 & 6.38 & $* * *$ \\
\hline $\mathrm{WF} \times \mathrm{CA}$ & 33.30 & 4.80 & 23.90 & 42.70 & 6.94 & $* * *$ \\
\hline $\mathrm{WF} \times \mathrm{NOS}$ & 5.99 & 1.49 & 3.06 & 8.92 & 4.01 & $* * *$ \\
\hline $\mathrm{CA} \times \mathrm{NOS}$ & 3.80 & 1.06 & 1.72 & 5.87 & 3.59 & $* * *$ \\
\hline $\mathrm{CA} \times \mathrm{ONS}$ & -2.07 & 1.32 & -4.65 & 0.51 & -1.57 & \\
\hline $\mathrm{CA} \times \mathrm{ONF}$ & -3.92 & 3.47 & -10.73 & 2.88 & -1.13 & \\
\hline $\mathrm{NOS} \times \mathrm{ONS}$ & -0.21 & 0.07 & -0.36 & -0.06 & -2.80 & $* *$ \\
\hline $\mathrm{NOS} \times \mathrm{ONF}$ & -0.97 & 0.42 & -1.79 & -0.14 & -2.29 & $*$ \\
\hline
\end{tabular}

Model equation: Model $1<-\operatorname{lmer}(\mathrm{RT} \sim 1+$ prevRT + prevACC + Length + WF:CA + WF:NOS + CA:NOS + CA:ONS + CA:ONF + NOS:ONS + NOS:ONF + (1|Subject $)+(1 \mid$ Item $)+(0+$ WF:CA + WF:NOS + CA:NOS + CA:ONS + CA:ONF + NOS:ONS + NOS:ONF || Subject $)$, data $=$ dataset, datacontrol $=$ lmerControl $($ optCtrl $=$ list $(\operatorname{maxfun}=20000)$ ). $\mathrm{CA}=$ context availability, NOS $=$ number of senses, ONS $=$ orthographic neighborhood size, $\mathrm{ONF}=$ orthographic neighborhood frequency, WF $=$ Zipf-scaled SUBTLEX $\mathrm{US}$ word frequency. $* p<.05, * * p<.01, * * * p<.001$.

dataset, but due to the lower number of participants and lesser amount of available data, the complex models presented above experienced convergence problems, and the estimates were not stable enough to be trustworthy.

That left us with data from the ELP and BLP megastudies to analyze. Due to concerns about the nonword characteristics used in the ELP lexical decision task (e.g., the nonwords appeared less word-like than the real words, which may have biased participants to rely more heavily on orthographic than on semantic features; see Rice, Beekhuizen, Dubrovsky,
Stevenson, \& Armstrong, 2018, for further discussion), we elected to use the lexical decision data from the BLP.

Of the 451 words analyzed in the section above, 391 were available in the BLP dataset. We extracted the response time, accuracy, and trial number for these words and processed the data in exactly the same manner described above. We then fit Model 1 to these data and found that our main interaction of interest, context availability and NOS, was still a significant predictor of lexical decision latencies $(b=2.33, S E=1.09, t=$ 2.13), as were the interactions of word frequency and context

Table 5 Fixed-effects estimates for Model 2

\begin{tabular}{|c|c|c|c|c|c|c|}
\hline & \multirow[t]{2}{*}{ Estimate } & \multirow[t]{2}{*}{$S E$} & \multicolumn{2}{|l|}{$95 \% \mathrm{CI}$} & \multirow[t]{2}{*}{$t$} & \multirow[t]{2}{*}{ Significance } \\
\hline & & & Lower Bound & Upper Bound & & \\
\hline Intercept & 646.70 & 7.98 & 631.03 & 662.33 & 81.00 & $* * *$ \\
\hline Previous-trial RT & 79.70 & 2.86 & 74.09 & 85.31 & 27.86 & $* * *$ \\
\hline Previous-trial accuracy & -73.98 & 3.59 & -81.00 & -66.95 & -20.63 & $* * *$ \\
\hline Length & 8.50 & 1.21 & 6.13 & 10.88 & 7.02 & $* * *$ \\
\hline $\mathrm{WF} \times$ Conc & 12.73 & 2.71 & 7.41 & 18.05 & 4.69 & $* * *$ \\
\hline $\mathrm{WF} \times \mathrm{NOS}$ & 11.24 & 1.54 & 8.22 & 14.27 & 7.29 & $* * *$ \\
\hline Cone $\times$ NOS & 0.80 & 0.37 & 0.08 & 1.52 & 2.18 & $*$ \\
\hline Cone $\times$ ONS & -0.13 & 0.38 & -0.87 & 0.62 & -0.34 & \\
\hline Conc $\times \mathrm{ONF}$ & -1.54 & 1.16 & -3.82 & 0.74 & -1.33 & \\
\hline $\mathrm{NOS} \times \mathrm{ONS}$ & -0.22 & 0.08 & -0.38 & -0.07 & -2.81 & $* *$ \\
\hline $\mathrm{NOS} \times \mathrm{ONF}$ & -1.13 & 0.47 & -2.06 & -0.20 & -2.39 & $*$ \\
\hline
\end{tabular}

Model equation: Model $2<-\operatorname{lmer}(\mathrm{RT} \sim 1+$ prevRT + prevACC + Length + WF:Conc + WF:NOS + Conc:NOS + Conc:ONS + Conc:ONF + NOS:ONS + NOS:ONF + (1|Subject $)+(1 \mid$ Item $)+(0+$ WF:Conc + WF:NOS + Conc:NOS + Conc:ONS + Conc:ONF + NOS:ONS + NOS:ONF || Subject $)$, data $=$ dataset, datacontrol $=$ lmerControl $($ optCtrl $=$ list $(\operatorname{maxfun}=20000))$. Conc $=$ concreteness, NOS $=$ number of senses, ONS $=$ orthographic neighborhood size, $\mathrm{ONF}=$ orthographic neighborhood frequency, WF $=$ Zipf-scaled SUBTLEX $\mathrm{US}$ word frequency. $* p<.05, * * p<.01, * * * p<.001$. 
Table 6 Random-effects estimates for Model 1

\begin{tabular}{lll}
\hline & Variance & $S D$ \\
\hline Item intercept & $1,165.00$ & 34.13 \\
$\mathrm{WF} \times \mathrm{CA} \mid$ Subject & 0.02 & 0.15 \\
$\mathrm{WF} \times \mathrm{NOS} \mid$ Subject & $<0.00$ & $<0.00$ \\
$\mathrm{CA} \times \mathrm{NOS} \mid$ Subject & $<0.00$ & $<0.00$ \\
$\mathrm{CA} \times \mathrm{ONS} \mid$ Subject & 5.79 & 2.41 \\
$\mathrm{CA} \times \mathrm{ONF} \mid$ Subject & 0.25 & 0.50 \\
$\mathrm{NOS} \times \mathrm{ONS} \mid$ Subject & $<0.00$ & $<0.00$ \\
NOS $\times \mathrm{ONF} \mid$ Subject & 342.30 & 18.50 \\
Subject intercept & $3,922.00$ & 62.62 \\
Residual & $18,810.00$ & 137.10 \\
\hline
\end{tabular}

availability $(b=22.64, S E=6.82, t=3.32)$, word frequency and $\operatorname{NOS}(b=7.06, S E=1.50, t=4.71)$, and NOS and orthographic neighborhood frequency $(b=-1.02, S E=$ $0.38, t=-2.70$. However, the main effect of previous-trial accuracy was no longer a significant predictor, and the interaction of NOS and orthographic neighborhood size was only marginally significant (see Tables 8 and 9). These findings will be considered further in the Discussion section.

\section{Discussion}

In this study, we examined the interactions of lexical and semantic variables during lexical processing. Using linear mixedeffects modeling (Baayen et al., 2008), we were able to provide a more inclusive account of the variables that affect processing during lexical decision, uniting for the first time a number of potential variables of interest that other researchers have identified separately. Linear-mixed effects models are capable of handling a large number of continuous variables, thereby eliminating the data loss from the dichotomization of variables that has occurred in a majority of previous studies in this area. In particular, we reexamined the interaction between NOS and

Table 7 Random-effects estimates for Model 2

\begin{tabular}{lll}
\hline & Variance & $S D$ \\
\hline Item intercept & $1,465.00$ & 38.28 \\
WF $\times$ Conc | Subject & 39.41 & 6.28 \\
WF $\times$ NOS | Subject & 0.96 & 0.98 \\
Conc $\times$ NOS | Subject & $<0.00$ & $<0.00$ \\
Conc $\times$ ONS | Subject & 0.12 & 0.35 \\
Conc $\times$ ONF | Subject & $<0.00$ & $<0.00$ \\
NOS $\times$ ONS | Subject & $<0.00$ & 0.03 \\
NOS $\times$ ONF | Subject & 0.01 & 0.08 \\
Subject intercept & $3,929.00$ & 62.68 \\
Residual & $18,880.00$ & 137.40 \\
\hline
\end{tabular}

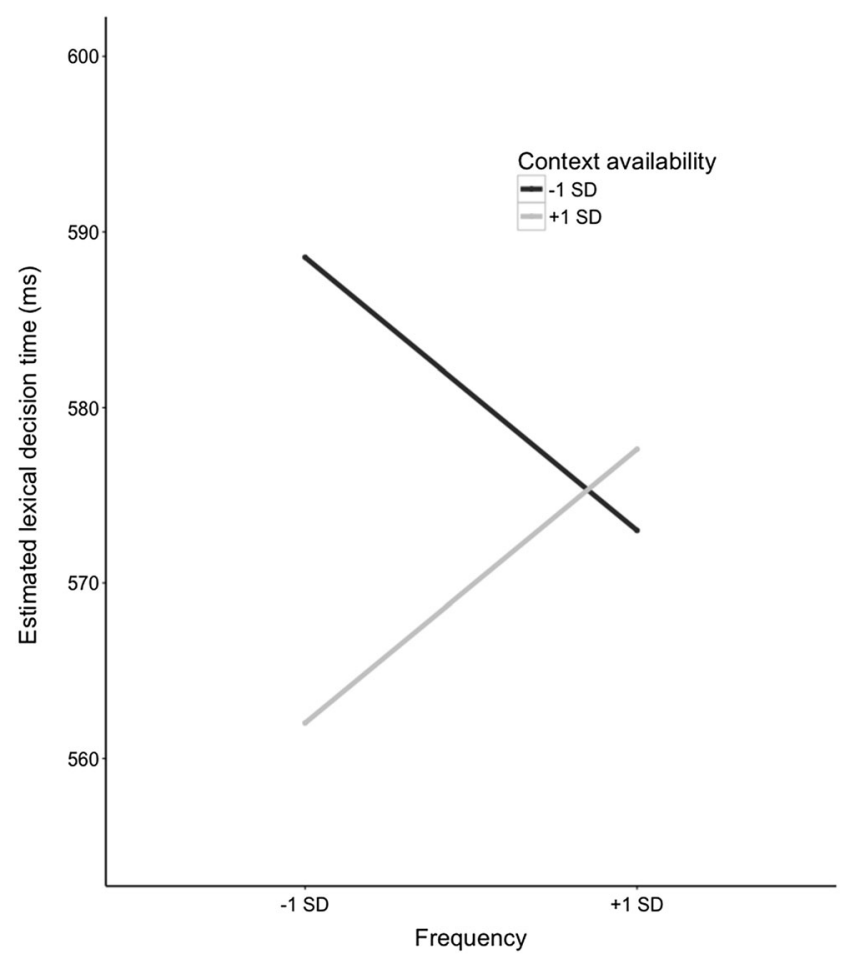

Fig. 1 Estimated lexical decision latencies (in milliseconds) for higher $(0.61)$ and lower $(-0.61)$ context availability and higher $(0.38)$ and lower $(-0.38)$ word frequency at one standard deviation above and below the means.

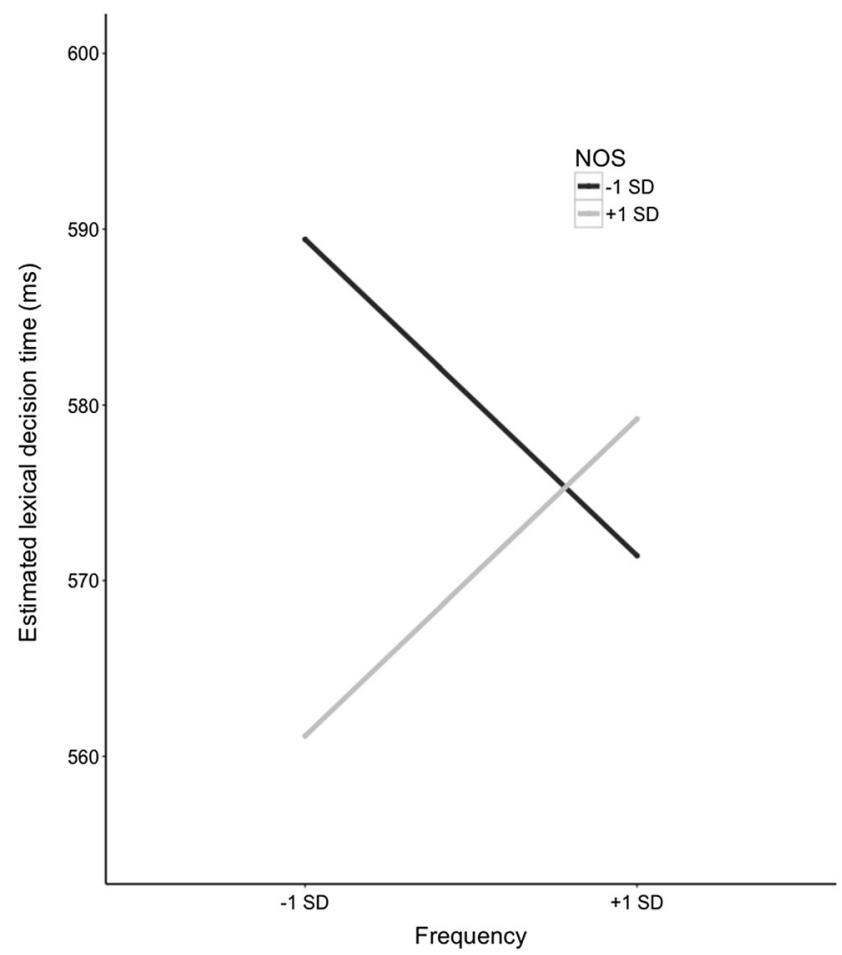

Fig. 2 Estimated lexical decision latencies (in milliseconds) for higher (3.91) and lower (-3.91) numbers of senses (NOS) and higher (0.38) and lower $(-0.38)$ word frequency at one standard deviation above and below the means. 


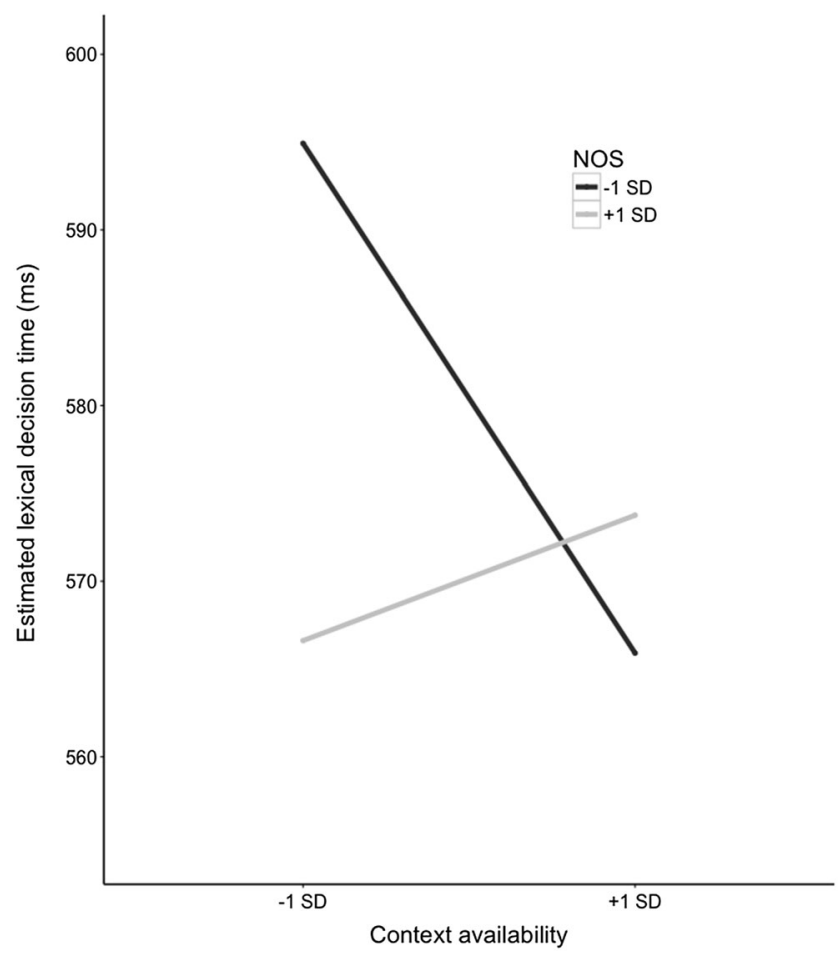

Fig. 3 Estimated lexical decision latencies (in milliseconds) for higher (3.91) and lower (-3.91) numbers of senses (NOS) and higher (0.61) and lower $(-0.61)$ context availability at one standard deviation above and below the means.

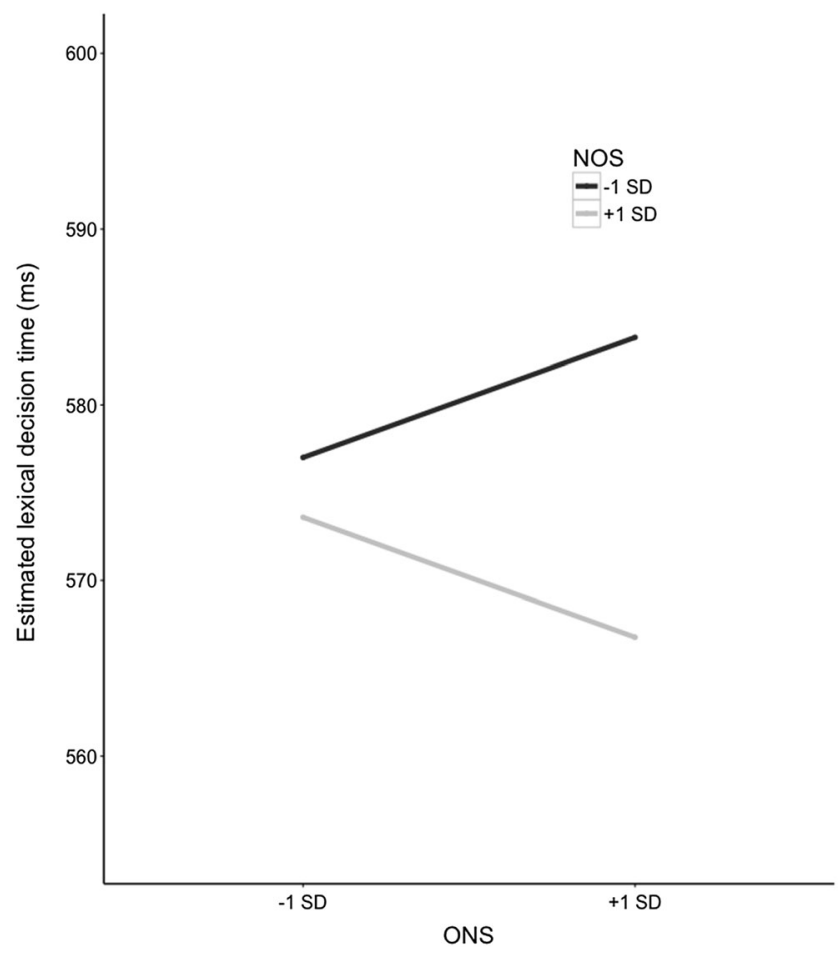

Fig. 4 Estimated lexical decision latencies (in milliseconds) for higher (3.91) and lower (-3.91) numbers of senses (NOS) and higher (7.28) and lower $(-1.08)$ orthographic neighborhood size (ONS) at one standard deviation above and below the means.

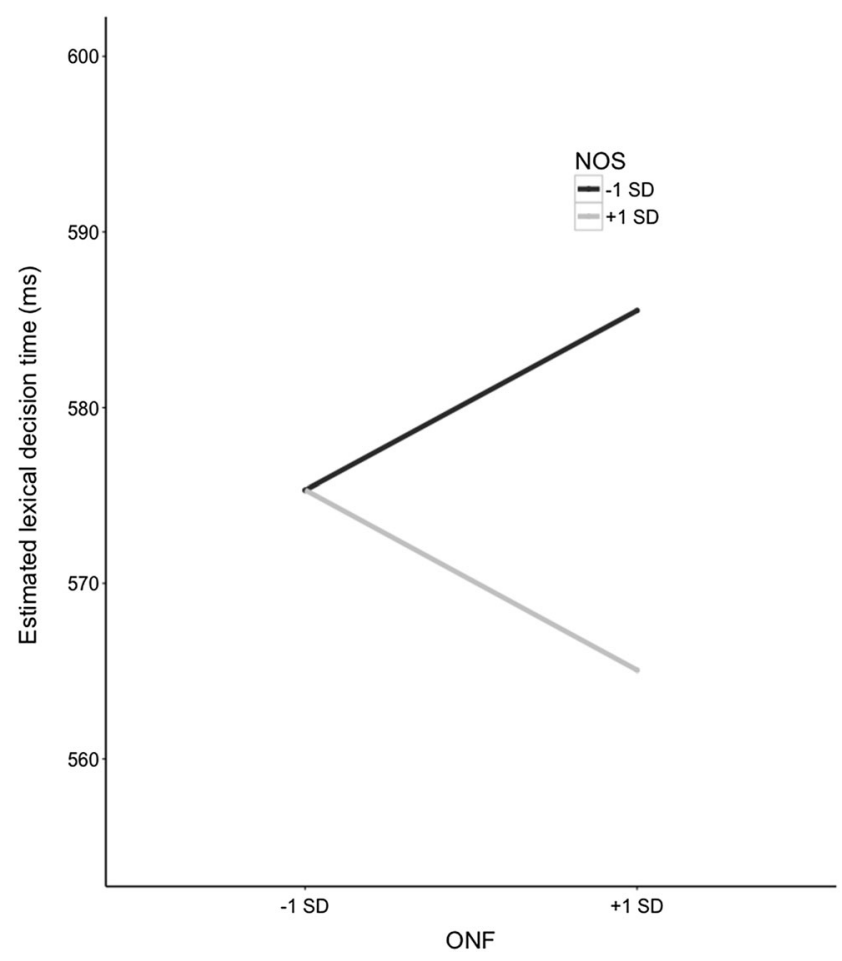

Fig. 5 Estimated lexical decision latencies (in milliseconds) for higher (3.91) and lower (-3.91) numbers of senses (NOS) and higher (2.04) and lower (1.36) orthographic neighborhood frequency (ONF) at one standard deviation above and below the means.

context availability first reported by Tokowicz and Kroll (2007), but now clarifying the effects of number of meanings and NOS. In what follows, we review the key findings of the present work. We discuss how our replication of the previously reported effects, in both a new participant sample and also in the BLP lexical decision data, can help resolve the contradictory reports of polysemy effects we reviewed in the introduction. We furthermore introduce several novel findings. We then turn to a discussion of possible theoretical mechanisms for each of the effects, because it has been a number of years since an article has addressed the complex pattern of interactions of this many lexical and semantic variables (see Gernsbacher, 1984, for the last comprehensive review of the topics discussed here). We conclude by discussing how our results provide support for existing theories of lexical and semantic processing, most notably the feedback activation account (Hino \& Lupker, 1996; Hino et al., 2002).

\section{Relationship to past findings}

We begin with a brief review of the key findings of this study and the relation of each to previous research. First, to address an ongoing debate in the literature, we tested whether context availability or concreteness is a better predictor of lexical decision latencies. In principle, it would be desirable to include context availability and concreteness in the same model, to 
Table 8 Fixed-effects estimates for the BLP model

\begin{tabular}{|c|c|c|c|c|c|c|}
\hline & & & $95 \% \mathrm{CI}$ & & & \\
\hline & Estimate & $S E$ & Lower Bound & Upper Bound & $t$ & Significance \\
\hline Intercept & 543.10 & 7.54 & 528.27 & 557.83 & 72.01 & $* * *$ \\
\hline Previous-trial RT & 74.84 & 3.28 & 68.42 & 81.26 & 22.85 & $* * *$ \\
\hline Previous-trial accuracy & 1.09 & 2.80 & -4.39 & 6.57 & 0.39 & \\
\hline Length & 9.44 & 1.44 & 6.61 & 12.26 & 6.55 & $* * *$ \\
\hline $\mathrm{WF} \times \mathrm{CA}$ & 22.64 & 6.82 & 9.26 & 36.01 & 3.32 & $* *$ \\
\hline $\mathrm{WF} \times \mathrm{NOS}$ & 7.06 & 1.50 & 4.12 & 10.00 & 4.71 & $* * *$ \\
\hline $\mathrm{CA} \times \mathrm{NOS}$ & 2.33 & 1.09 & 0.18 & 4.47 & 2.13 & $*$ \\
\hline $\mathrm{CA} \times \mathrm{ONS}$ & -0.73 & 1.20 & -3.09 & 1.63 & -0.60 & \\
\hline $\mathrm{CA} \times \mathrm{ONF}$ & -3.38 & 3.29 & -9.83 & 3.06 & -1.03 & \\
\hline NOS $\times$ ONS & -0.13 & 0.07 & -0.26 & 0.01 & -1.86 & $\dagger$ \\
\hline $\mathrm{NOS} \times \mathrm{ONF}$ & -1.02 & 0.38 & -1.76 & -0.28 & -2.70 & $* *$ \\
\hline
\end{tabular}

Model equation: Model $1<-\operatorname{lmer}(\mathrm{RT} \sim 1+$ prevRT + prevACC + Length + WF:CA + WF:NOS + CA:NOS + CA:ONS + CA:ONF + NOS:ONS + NOS:ONF + (1|Subject $)+(1 \mid$ Item $)+(0+$ WF:CA + WF:NOS + CA:NOS + CA:ONS + CA:ONF + NOS:ONS + NOS:ONF $\|$ Subject $)$, data $=$ dataset, datacontrol $=$ lmerControl $($ optCtrl $=$ list $(\operatorname{maxfun}=20000)$ ). CA $=$ context availability, NOS $=$ number of senses, ONS $=$ orthographic neighborhood size, $\mathrm{ONF}=$ orthographic neighborhood frequency, WF $=$ Zipf-scaled SUBTLEX $\mathrm{US}_{\mathrm{S}}$ word frequency. ${ }^{\dagger} p<.1,{ }^{*} p<.05, * * p<.01, * * * p<.001$.

test whether the context availability advantage is independent of the concreteness advantage. However, we found that context availability and concreteness are highly correlated, and entering them simultaneously into a mixed-effect model could thus result in erratic estimates of all predictors in the model because of the high amount of multicollinearity. We instead compared the performance of a model with context availability but not concreteness to an otherwise identical model with concreteness but not context availability, and we found that the model with only context availability performed better than the model with only concreteness.

Our findings thus support the idea that the inconsistencies in studies of the concreteness effect may have been due in part to concreteness being confounded with context availability. For example, whereas James (1975) and de Groot (1989) reported concreteness/imageability advantages but did not test for the effects of context availability, several researchers have

Table 9 Random-effects estimates for BLP model

\begin{tabular}{lll}
\hline & Variance & $S D$ \\
\hline Item intercept & 790.20 & 28.11 \\
WF $\times$ CA | Subject & 209.00 & 14.46 \\
WF $\times$ NOS | Subject & 0.61 & 0.78 \\
$\mathrm{CA} \times \mathrm{NOS} \mid$ Subject & $<0.00$ & 0.02 \\
$\mathrm{CA} \times \mathrm{ONS} \mid$ Subject & 0.18 & 0.42 \\
$\mathrm{CA} \times \mathrm{ONF} \mid$ Subject & 16.14 & 4.02 \\
$\mathrm{NOS} \times \mathrm{ONS} \mid$ Subject & $<0.00$ & $<0.00$ \\
$\mathrm{NOS} \times \mathrm{ONF} \mid$ Subject & $<0.00$ & $<0.00$ \\
Subject intercept & $3,679.00$ & 60.65 \\
Residual & $12,430.00$ & 111.51 \\
\hline
\end{tabular}

demonstrated that the concreteness advantage disappeared or was reversed once context availability was controlled (Kousta et al., 2011; Schwanenflugel et al., 1988). We suggest that at least some previous reports of the concrete-word advantage reported an advantage that was actually due to context availability; that is, apparent concreteness effects actually arise from differences between concrete and abstract words in the average availability of contextual information, as has been suggested by others (e.g., Schwanenflugel et al., 1988; Schwanenflugel \& Shoben, 1983; van Hell \& de Groot, 1998b).

Second, consistent with the findings of Tokowicz and Kroll (2007), we reported an interaction of ambiguity and context availability. This replication informs our understanding of both the context availability effect and the ambiguity advantage. When this interaction is considered in terms of the context availability effect, we see that the context availability effect is strongest for words with few senses. When words have few senses, they receive less beneficial activation from other noncompeting meanings, and therefore are disadvantaged during lexical decision relative to words with more senses. Thus, words with fewer senses seem to particularly benefit from having greater context availability to aid in recognition, and are particularly disadvantaged when context availability is also low. When this interaction is considered in terms of the polysemy effect, we see that the effect of NOS is greatest for words lower in context availability. As before, words lower in context availability seem to benefit from having more senses to support recognition, and these words are also particularly disadvantaged when they also have fewer senses. These results are of theoretical interest because this interaction demonstrates that semantic information can 
play a strong role in lexical processing, and they offer support for models of lexical processing that incorporate semantic feedback to orthographic levels (i.e., Hino \& Lupker, 1996; Hino et al., 2002). We discuss this point in more depth in the last section of this Discussion.

Third, we reported interactions between NOS and both orthographic neighborhood frequency and orthographic neighborhood size. The interaction of NOS and orthographic neighborhood size illustrates that words with a larger orthographic neighborhood size are more affected by NOS than are words with a smaller orthographic neighborhood size. Words that have a larger orthographic neighborhood size but are lower in NOS are the slowest to be recognized, whereas words that have a larger orthographic neighborhood size but are higher in NOS are the fastest to be recognized. Similarly, the interaction of NOS and orthographic neighborhood frequency illustrates that there is almost no effect of NOS on words that have few higher-frequency neighbors, but conversely, there is a strong effect of NOS on words that have more higherfrequency neighbors. Specifically, words that have more higher-frequency neighbors but few senses are disadvantaged relative to words that have a greater number of senses.

We also tested the higher-order interaction of orthographic neighborhood size, orthographic neighborhood frequency, and NOS, which we hypothesized might be present in light of a past report by Ferraro and Hansen (2002). To examine this, we tested the three-way interaction in both Models 1 and 2 , but this interaction term was not significant in either model. This discrepancy is likely due to methodological and analytical differences. Ferraro and Hansen's words comprised homonyms and unambiguous words, whereas all of our words had a single meaning but ranged from one to 35 senses. This suggests the possibility that homonyms or unambiguous words may be sensitive to the effects of orthographic information in different ways than polysemes. Alternatively, Ferraro and Hansen dichotomized all of their key variables and conducted subjects-only analyses of variance, whereas we chose to keep our variables continuous and examined the effects of subjects and items with linear mixed effects models. It is possible that these different analytical choices were enough to cause the divergent findings. Although we can only speculate as to the true cause, it should be noted that although the precise interactions we have reported diverge from Ferraro and Hansen, the conclusions we drew are largely in agreement: Ambiguity effects are sensitive to the influence of orthographic neighborhood variables, and the presence of these interactions argues in favor of models of word recognition that highlight the interactive nature of lexical processing (e.g., Hino \& Lupker, 1996; McClelland \& Rumelhart, 1981).

Fourth, we tested interactions between context availability and both orthographic neighborhood frequency and orthographic neighborhood size. In agreement with Samson and Pillon (2004), we report that the interaction of orthographic neighborhood size and context availability was not significant. But in contrast to the findings of Samson and Pillon, we did not find a significant interaction of orthographic neighborhood frequency and context availability. This difference may have been due to the inclusion in our model of the significant interaction of orthographic neighborhood frequency and NOS. NOS and context availability function similarly (as sources of semantic information) during lexical processing, but the Samson and Pillon study did not account for the effects of ambiguity. Therefore, the interaction between orthographic neighborhood frequency and context availability reported by Samson and Pillon might have actually been due to a broader interaction of lexical and semantic variables during lexical processing, which NOS is actually better suited to describe than is context availability.

Fifth, and finally, we examined the influence of one other lexical variable: word frequency. We reported interactions of word frequency with both NOS and context availability, such that the polysemy and context availability effects were larger for lower-frequency words. This finding is in line with previous reports of interactions of frequency and ambiguity (e.g., Jastrzembski, 1981; Pexman et al., 2004), as well as of frequency and concreteness/context availability (e.g., de Groot, 1989).

\section{Replication using British Lexicon Project lexical decision data}

A strength of the present work is that we provide evidence that our main interaction of interest, context availability and NOS, replicated when we examined lexical decision data from the BLP megastudy. Similarly, we replicated the significant interactions of word frequency and context availability, word frequency and NOS, and NOS and orthographic neighborhood frequency. We failed to replicate the interaction of NOS and orthographic neighborhood size (although note that this interaction was marginally significant, $b=-0.13, S E=0.07, t=-1.86, p=.06$ ). The fact that nearly all of the results that we report above replicated in the BLP dataset strengthens our confidence that the results we report are replicable effects and not simply peculiarities of the particular lexical decision dataset or model we have presented in the present work.

\section{Implications for theoretical models of lexico-semantic processing}

We now turn to discussing the theoretical implications of our findings. A key question that arises, given our results, is how to understand the influence of semantic variables such as polysemy and context availability during lexical decision, especially with regard to their interactions with lexical variables such as word frequency and orthographic neighborhood size and frequency. We suggest that only in the absence of strong 
lexical representations, or the presence of competition at the lexical level, are semantic effects able to arise during lexical decision.

As we reviewed in the introduction, PDP models of word recognition have successfully modeled ambiguity effects using networks that capture the complex interactions between lexical and semantic influences during lexical processing. In what follows, we will describe our results using the feedback activation account first proposed by Hino and Lupker (1996; see also Hino et al., 2002), which we feel is best suited to explaining the present results. Specifically, we explore whether the feedback activation account can accommodate the key findings of this article: (1) the interaction of polysemy and context availability, (2) the interactions of polysemy and context availability with word frequency, and (3) the interactions of polysemy with orthographic neighborhood variables.

The feedback activation account (Hino \& Lupker, 1996; Hino et al., 2002) represents words as patterns of activation over clusters of units representing word characteristics. These units are connected within a hierarchical network, and the connections among units are strengthened or weakened as learning proceeds. Units have activation thresholds above which they become active and pass activation on to the other units to which they are connected. During lexical processing, activation begins at orthographic levels and spreads in a feed-forward manner to semantic levels, and the semantic levels in turn feed activation backward to orthographic levels.

Within this framework, ambiguity effects arise due to feedback activation from the semantic level to the orthographic level. This is because ambiguous words, by definition, have multiple semantic representations, and therefore benefit from a greater amount of activation over semantic units and a greater amount of semantic feedback to orthographic units than do unambiguous words, which have only a single semantic representation. Polysemes, in particular, benefit from this feedback activation, because they have a single orthographic form that maps to multiple related semantic representations. In contrast, unambiguous words have a single orthographic form that maps directly to a single semantic representation. Therefore, polysemes may benefit from increased activation at the semantic level relative to unambiguous words, and the effects of this increased activation are amplified by the feedback activation from the semantic level to the orthographic level.

In addition to these differences, there can be considerable variation in how much orthographic, phonological, and semantic activation is available during lexical decision, which is determined by word characteristics such as NOS, context availability, orthographic neighborhood variables, or lexical frequency. Greater amounts of lexical information (as would be the case for both higher-frequency words and words with more orthographic neighbors) is depicted with more active representational units within the lexical level, and similarly, greater amounts of semantic information (as would be the case for words higher in NOS or context availability) is depicted with more active representational units within the semantic level. These variations in activation within the orthographic and semantic levels of a processing network help explain the general finding that words that are low in both lexical and semantic information are particularly disadvantaged during word recognition, whereas words that are low in lexical information but high in semantic information are buffered from this disadvantage. For example, if a word has few active orthographic representational units (perhaps due to low frequency), only weak activation will feed into the semantic level of the network. If the word has enough semantic representational units active (i.e., it is high in NOS or context availability), activation will both feed forward to push the word toward a recognition threshold, and also feed backward to the orthographic units and increase the previously weak activation within that level; this, in turn, feeds forward to the semantic level and increases the overall activation in the network. In contrast, if a word has too few semantic units active (i.e., is low in NOS or context availability), it will neither reach the recognition threshold nor send sufficient activation back to orthographic units.

With these principles in mind, we consider our first key finding: the interaction of NOS and context availability. Specifically, we reported that the context availability effect is strongest for words that have few senses. In the context of the feedback activation account, words with few senses have fewer semantic units activated than words with more senses, and words that are lower in context availability have fewer semantic units activated than words that are higher in context availability. Thus, when a word has many senses, it may already have enough semantic activation for it not to need additional semantic activation from context to reach a recognition threshold, thus producing a processing advantage for words higher in NOS. However, if there is insufficient semantic activation due to lower NOS, words that are higher in context availability may benefit from the additional semantic activation due to context availability.

Our second key finding is that both semantic variables (NOS and context availability) interact strongly with the lexical variable word frequency. Specifically, we report that the context availability and NOS effects are strongest for lower-frequency words. Lower-frequency words have fewer active orthographic and phonological units sending activation forward to semantic units, and this impoverished activation may be insufficient to allow a word to reach a recognition threshold. When this occurs, feedback activation from the semantic system becomes important and therefore words with more active semantic units (e.g., words that are higher in NOS or context availability) are pushed toward recognition more quickly than words with fewer active semantic units. 
Our last finding was that NOS interacts with both orthographic neighborhood size and frequency. First, we reported that NOS effects appear only for words with more higherfrequency neighbors. When words have more higherfrequency orthographic neighbors, greater competition within the orthographic level might prevent orthographic units from obtaining sufficient activation to reach threshold, and as a result, semantic activation and semantic feedback are required in order to push a word toward recognition. Second, we reported that words that are higher in NOS and higher in orthographic neighborhood size are the fastest to be recognized. When words have more orthographic neighbors, they receive greater (noncompeting) activation at the orthographic level, and this benefit is compounded by the greater semantic activation and feedback of words with greater NOS.

In summary, the feedback activation account (Hino \& Lupker, 1996; Hino et al., 2002) is able to explain the key findings of this study. However, it is important to note that the present study only considered the processing of polysemes and unambiguous words, and it excluded homonyms and other types of ambiguous words from consideration. Hino et al. (2002) described several concerns about the generalizability of this model to all types of ambiguous words, chiefly that some findings suggest that semantic processing and semantic feedback during lexical decision might be modulated by the degree of semantic similarity (or relatedness) of the multiple meanings of ambiguous words. Further studies will be needed to investigate this possibility.

\section{Conclusion}

This research advances the study of semantic ambiguity and lexical access by providing the most inclusive account currently available of the complex interactions between lexical and semantic variables during the lexical processing of polysemes and unambiguous words. Past studies have examined only subsets of the variables included in the present work, a limitation that we were able to overcome due to the use of linear mixed-effect models. This modeling approach allowed us to examine the interactions of a large number of lexical and semantic variables during lexical decision, and in doing so to shed light on why the literature contains numerous inconsistent reports of the effects of the polysemy, concreteness/ context availability, and orthographic neighborhood variables. We suggest that these inconsistencies have been largely due to failures to appropriately model the complexity of the interactions between a large number of lexical and semantic variables during lexical processing.

We presented three key findings. First, we reported an interaction between context availability and polysemy, such that words that both are low in context availability and have few related senses are especially disadvantaged, as was originally reported by Tokowicz and Kroll (2007). Second, we demonstrated that both the polysemy and context availability effects depend on word frequency, such that they are stronger for lower-frequency than for higher-frequency words. Third, we reported interactions of both polysemy and context availability with orthographic neighborhood variables: the effect of NOS appears only for words with more higher-frequency neighbors, and words that are higher in NOS and higher in orthographic neighborhood size are especially advantaged during lexical decision. A strength of the present study is that these results were largely replicated using data from the BLP megastudy; out of all these findings, the only effect that failed to significantly replicate in the BLP was the interaction of NOS and orthographic neighborhood size, and that effect was marginally significant, as well.

At a broader level, this research provides support for the context availability hypothesis and for feedback activation accounts of lexical processing. We hope this will encourage future researchers in this area to consider the roles that contextual information and semantic feedback may play during lexical processing. The results of this study also provide insight into the nature of polysemy effects and directions for future research on this topic. In particular, our study highlights the importance of considering the continuous nature of polysemy, rather than classifying polysemous words into categories based on NOS. However, recent research has suggested that there may be differential effects of ambiguity even within polysemous words. For instance, metonyms are known to be processed more quickly than metaphors (e.g., Eddington \& Tokowicz, 2015), but thus far no one has examined whether these different types of polysemy interact differently with context availability. Future research should take this into account and further explore how the results outlined in this article might or might not be present across other tasks and throughout the time course of lexical processing (e.g., Armstrong \& Plaut, 2016).

Author note We thank Blair Armstrong for helpful comments on the manuscript, as well as PLUM lab research assistants for help with data collection. During the writing of this article, C.A.R. was supported by National Institutes of Health Grant T32 GM 81760, and N.T. was funded by National Institutes of Health Grant R01 HD075800. No potential conflicts of interest are reported by the authors.

\section{References}

Aiken, L. S., \& West, S. G. (1991). Multiple regression: Testing and interpreting interactions. Thousand Oaks, CA: Sage.

Armstrong, B. C., \& Plaut, D. C. (2008). Settling dynamics in distributed networks explain task differences in semantic ambiguity effects: Computational and behavioral evidence. In B. C. Love, K. 
McRae, \& V. M. Sloutsky (Eds.), Proceedings of the 30th Annual Meeting of the Cognitive Science Society (pp. 273-278). Austin, TX: Cognitive Science Society.

Armstrong, B. C., \& Plaut, D. C. (2016). Semantic ambiguity effects in lexical processing: A neural-network account based on semantic settling dynamics (Unpublished manuscript). Department of Psychology, Carnegie Mellon University, Pittsburgh, PA.

Armstrong, B. C., Tokowicz, N., \& Plaut, D. C. (2012). eDom: Norming software and relative meaning frequencies for 544 English homonyms. Behavior Research Methods, 44, 1015-1027. doi:https:// doi.org/10.3758/s13428-012-0199-8

Azuma, T., \& Van Orden, G. C. (1997). Why SAFE is better than FAST: The relatedness of a word's meanings affects lexical decision times. Journal of Memory and Language, 36, 484-504. doi:https://doi.org/ 10.1006/jmla.1997.2502

Baayen, R. H. (2008). Analyzing linguistic data: A practical introduction to statistics using R. New York, NY: Cambridge University Press.

Baayen, R. H., Davidson, D. J., \& Bates, D. M. (2008). Mixed-effects modeling with crossed random effects for subjects and items. Journal of Memory and Language, 59, 390-412. doi:https://doi. org/10.1016/j.jml.2007.12.005

Balota, D. A., Yap, M. J., Cortese, M. J., Hutchison, K. A., Kessler, B., Loftis, B., . . . Treiman, R. (2007). The English lexicon project. Behavior Research Methods, 39, 445-459. doi:https://doi.org/10. 3758/BF03193014

Barr, D. J., Levy, R., Scheepers, C., \& Tily, H. J. (2013). Random effects structure for confirmatory hypothesis testing: Keep it maximal. Journal of Memory and Language, 68. doi:https://doi.org/10.1016/ j.jml.2012.11.001

Bates, D., Maechler, M., Bolker, B., \& Walker, S. (2014). lme4: Linear mixed-effects models using Eigen and S4 (R package version 1.1-7). Retrieved from http://CRAN.R-project.org/package=lme4

Begg, I., \& Paivio, A. (1969). Concreteness and imagery in sentence meaning. Journal of Verbal Learning and Verbal Behavior, 8, $821-827$.

Bissonnette, V., Ickes, W., Bernstein, I., \& Knowles, E. (1990). Item variances and median splits: Some discouraging and disquieting findings. Journal of Personality, 58, 595-601.

Broadbent, D. E. (1967). Word-frequency effect and response bias. Psychological Review, 74, 1-15.

Brysbaert, M., \& New, B. (2009). Moving beyond Kučera and Francis: A critical evaluation of current word frequency norms and the introduction of a new and improved word frequency measure for American English. Behavioral Research Methods, 41, 977-990. doi:https://doi.org/10.3758/BRM.41.4.977

Campos, A., \& González, M. A. (1992). Imagery, concreteness, emotionality, and meaningfulness values of words: replication and extension. Perceptual and Motor Skills, 74, 691-696.

Cohen, J. (1983). The cost of dichotomization. Applied Psychological Measurement, 7, 249-253.

Coltheart, M., Davelaar, E., Jonasson, J. F., \& Besner, D. (1977). Access to the internal lexicon. In S. Dornic (Ed.), Attention and performance VI (pp. 535-555). Hillsdale, NJ: Erlbaum.

Coltheart, M., Rastle, K., Perry, C., Langdon, R., \& Ziegler, J. (2001). DRC: A dual route cascaded model of visual word recognition and reading aloud. Psychological Review, 108, 204-256. doi:https://doi. org/10.1037/0033-295X.108.1.204

de Groot, A. M. (1989). Representational aspects of word imageability and word frequency as assessed through word association. Journal of Experimental Psychology: Learning, Memory, and Cognition, 15, 824-845. doi:https://doi.org/10.1037/0278-7393.15.5.824

Eddington, C. M., \& Tokowicz, N. (2015). How meaning similarity influences ambiguous word processing: The current state of the literature. Psychonomic Bulletin \& Review, 22, 13-37. doi:https://doi. org/10.3758/s13423-014-0665-7
Ferraro, F. R., \& Hansen, C. L. (2002). Orthographic neighbourhood size, number of word meanings, and number of higher frequency neighbours. Brain and Language, 82, 200-205. doi:https://doi.org/10. 1016/S0093-934X(02)00016-0

Frank, A. (2011). Diagnosing collinearity in mixed models from lme4 (HLP/Jaeger lab blog). Retrieved from https://hlplab.wordpress. com/2011/02/24/diagnosing-collinearity-in-lme4/

Forster, K. I., \& Chambers, S. M. (1973). Lexical access and naming time. Journal of Verbal Learning and Verbal Behavior, 12, 627635. doi:https://doi.org/10.1016/S0022-5371(73)80042-8

Gernsbacher, M. A. (1984). Resolving 20 years of inconsistent interactions between lexical familiarity and orthography, concreteness, and polysemy. Journal of Experimental Psychology: General, 113, 256281. doi:https://doi.org/10.1037/0096-3445.113.2.256

Gilhooly, K. J., \& Logie, R. H. (1980). Age-of-acquisition, imagery, concreteness, familiarity, and ambiguity measures for 1,944 words. Behavior Research Methods \& Instrumentation, 12, 395-427. doi: https://doi.org/10.3758/BF03201693

Hino, Y., \& Lupker, S. J. (1996). Effects of polysemy in lexical decision and naming: An alternative to lexical access accounts. Journal of Experimental Psychology: Human Perception and Performance, 22, 1331-1356. doi:https://doi.org/10.1037/0096-1523.22.6.1331

Hino, Y., Lupker, S. J., \& Pexman, P. M. (2002). Ambiguity and synonymy effects in lexical decision, naming, and semantic categorization tasks: Interactions between orthography, phonology, and semantics. Journal of Experimental Psychology: Learning, Memory, and Cognition, 28, 686-713. doi:https://doi.org/10.1037/0278-7393.28. 4.686

Hino, Y., Lupker, S. J., Sears, C. R., \& Ogawa, T. (1998). The effects of polysemy for Japanese katakana words. Reading and Writing, 10, 395-424. doi:https://doi.org/10.1023/A:1008060924384

Hughes, J. (2018). reghelper: Helper functions for regression analysis ( $R$ package version 0.3.4). Retrieved from http://CRAN.R-project.org/ package $=$ reghelper

Jaeger, T. F. (2010). Redundancy and reduction: Speakers manage syntactic information density. Cognitive Psychology, 61, 23-62. doi: https://doi.org/10.1016/j.cogpsych.2010.02.002

Jager, B., \& Cleland, A. A. (2016). Polysemy advantage with abstract but not concrete words. Journal of Psycholinguistic Research, 45, 143 156. doi:https://doi.org/10.1007/s10936-014-9337-z

James, C. T. (1975). The role of semantic information in lexical decisions. Journal of Experimental Psychology: Human Perception and Performance, 104, 130-136. doi:https://doi.org/10.1037/00961523.1.2.130

Jastrzembski, J. E. (1981). Multiple meanings, number of related meanings, frequency of occurrence, and the lexicon. Cognitive Psychology, 13, 278-305. doi:https://doi.org/10.1016/00100285(81)90011-6

Kawamoto, A. H., Farrar, W. T., \& Kello, C. T. (1994). When two meanings are better than one: Modeling the ambiguity advantage using a recurrent distributed network. Journal of Experimental Psychology: Human Perception and Performance, 20, 1233-1247. doi:https:// doi.org/10.1037/0096-1523.20.6.1233

Keuleers, E., Lacey, P., Rastle, K., \& Brysbaert, M. (2012). The British Lexicon Project: Lexical decision data for 28,730 monosyllabic and disyllabic English words. Behavior Research Methods, 44, 287304. doi:https://doi.org/10.3758/s13428-011-0118-4

Klein, D. E., \& Murphy, G. L. (2001). The representation of polysemous words. Journal of Memory and Language, 45, 259-282.

Klepousniotou, E. (2002). The processing of lexical ambiguity: Homonymy and polysemy in the mental lexicon. Brain and Language, 81, 205-223. doi:https://doi.org/10.1006/brln.2001.2518

Kousta, S.-T., Vigliocco, G., Vinson, D. P., Andrews, M., \& Del Campo, E. (2011). The representation of abstract words: Why emotion matters. Journal of Experimental Psychology: General, 140, 14-34. doi:https://doi.org/10.1037/a0021446 
Kroll, J. F., \& Merves, J. S. (1986). Lexical access for concrete and abstract words. Journal of Experimental Psychology: Learning Memory and Cognition, 12, 92-107. doi:https://doi.org/10.1037/ 0278-7393.12.1.92

Kučera, H., \& Francis, W. N. (1967). Computational analysis of present day American English. Providence, RI: Brown University Press.

Kuznetsova, A., Brockhoff, P. B. and Christensen, R. H. B. (2017). lmerTest package: Tests in linear mixed effects models. Journal of Statistical Software, 82, 1-26. doi:https://doi.org/10.18637/jss. v082.i13

Maxwell, S. E., \& Delaney, H. D. (1993). Bivariate median splits and spurious statistical significance. Psychological Bulletin, 113, 181190.

McClelland, J. L., \& Rumelhart, D. E. (1981). An interactive activation model of context effects in letter perception: 1 . An account of basic findings. Psychological Review, 88, 375-407. doi:https://doi.org/10. 1037/0033-295X.88.5.375

Miller, G. A. (1995). WordNet: A lexical database for English. Communications of the ACM, 38, 39-41.

Mirman, D., Strauss, T. J., Dixon, J. A., \& Magnuson, J. S. (2010). Effect of representational distance between meanings on recognition of ambiguous spoken words. Cognitive Science, 34, 161-173. doi: https://doi.org/10.1111/j.1551-6709.2009.01069.x

Paivio, A. (1968). A factor-analytic study of word attributes and verbal learning. Journal of Verbal Learning and Verbal Behavior, 7, 41-49.

Paivio, A. (1971). Imagery and verbal processes. New York, NY: Holt, Rinehart, \& Winston.

Paivio, A., Yuille, J. C., \& Madigan, S. A. (1968). Concreteness, imagery, and meaningfulness values for 925 nouns. Journal of Experimental Psychology, 76(1, Pt. 2), 1-25. doi:https://doi.org/10.1037/ h0025327

Pexman, P. M., Hino, Y., \& Lupker, S. J. (2004). Semantic ambiguity and the process of generating meaning from print. Journal of Experimental Psychology: Learning, Memory, and Cognition, 30, 1252-1270. doi:https://doi.org/10.1037/0278-7393.30.6.1252

Plaut, D. C., \& Shallice, T. (1993). Deep dyslexia: A case study of connectionist neuropsychology. Cognitive Neuropsychology, 10, 377500. doi:https://doi.org/10.1080/02643299308253469

Reichle, E. D., Pollatsek, A., Fisher, D. L., \& Rayner, K. (1998). Toward a model of eye movement control in reading. Psychological Review, $105,125-157$.

Reilly, J., \& Kean, J. (2007). Formal distinctiveness of high- and lowimageability nouns: Analyses and theoretical implications. Cognitive Science, 31, 157-168. doi:https://doi.org/10.1080/ 03640210709336988

Rice, C. A., Beekhuizen, B., Dubrovsky, V., Stevenson, S., \& Armstrong, B. C. (2018). A comparison of homonym meaning frequency estimates derived from movie and television subtitles, free association, and explicit ratings. Behavior Research Methods. Advance online publication. doi:https://doi.org/10.3758/s13428-018-1107-7

Richardson, J. T. E. (1975). Imagery, concreteness, and lexical complexity. Quarterly Journal of Experimental Psychology, 27, 211-223. doi:https://doi.org/10.1080/14640747508400481

Rodd, J., Gaskell, G., \& Marslen-Wilson, W. (2002). Making sense of semantic ambiguity: Semantic competition in lexical access. Journal of Memory and Language, 46, 245-266. doi:https://doi.org/10. 1006/jmla.2001.2810

Rubenstein, H., Garfield, L., \& Millikan, J. A. (1970). Homographic entries in the internal lexicon. Journal of Verbal Learning and Verbal Behavior, 9, 487-494.

Rumelhart, D. E., \& McClelland, J. L. (1982). An interactive activation model of context effects in letter perception: Part 2. The contextual enhancement effect and some tests and extensions of the model. Psychological Review, 89, 60-94.
Samson, D., \& Pillon, A. (2004). Orthographic neighbourhood and concreteness effects in the lexical decision task. Brain and Language, 91, 252-264. doi:https://doi.org/10.1016/j.bandl.2004.03.001

Schwanenflugel, P. J., Harnishfeger, K. K., \& Stowe, R. W. (1988). Context availability and lexical decisions for abstract and concrete words. Journal of Memory and Language, 27, 499-520. doi:https:// doi.org/10.1016/0749-596X(88)90022-8

Schwanenflugel, P. J., \& Shoben, E. J. (1983). Differential context effects in the comprehension of abstract and concrete verbal materials. Journal of Experimental Psychology: Learning, Memory, and Cognition, 9, 82-102.

Schwanenflugel, P. J., \& Stowe, R. W. (1988). Context availability and the processing of abstract and concrete words in sentences. Reading Research Quarterly, 24, 114-126. doi:https://doi.org/10.3758/ BF03208259

Seidenberg, M. S., \& McClelland, J. L. (1989). A distributed, developmental model of word recognition and naming. Psychological Review, 96, 523-568. doi:https://doi.org/10.1037/0033-295X.96.4. 523

Spreen, O., \& Shulz, R. W. (1966). Parameters of abstraction, meaningfulness, and pronunciability for 329 nouns. Journal of Verbal Learning and Verbal Behavior, 5, 459-468.

Tokowicz, N., \& Kroll, J. F. (2007). Number of meanings and concreteness: Consequences of ambiguity within and across languages. Language and Cognitive Processes, 22, 727-779. doi:https://doi. org/10.1080/01690960601057068

Tokowicz, N., \& Warren, T. (2008). Quantification and statistics. In L. Wei \& M. Moyer (Eds.), The Blackwell guide to research methods in bilingualism and multilingualism (pp. 214-231). Malden, MA: Blackwell.

Tokowicz, N., Michael, E. B., \& Kroll, J. F. (2004). The roles of studyabroad experience and working-memory capacity in the types of errors made during translation. Bilingualism: Language and Cognition, 7, 255-272. doi:https://doi.org/10.1017/ S1366728904001634

Tolentino, L. C., \& Tokowicz, N. (2009). Are pumpkins better than heaven? An ERP investigation of order effects in the concrete-word advantage. Brain \& Language, 110, 12-22. doi:https://doi.org/10. 1016/j.bandl.2009.01.001

van Hell, J. G., \& de Groot, A. M. B. (1998a). Conceptual representation in bilingual memory: Effects of concreteness and cognate status in word association. Bilingualism: Language and Cognition, 1, 193211. doi:https://doi.org/10.1017/S1366728998000352

van Hell, J. G., \& de Groot, A. M. B. (1998b). Disentangling context availability and concreteness in lexical decision and word translation. Quarterly Journal of Experimental Psychology, 51A, 41-63. doi:https://doi.org/10.1080/713755752

van Heuven, W. J. B., Mandera, P., Keuleers, E., \& Brysbaert, M. (2014). SUBTLEX-UK: A new and improved word frequency database for British English. Quarterly Journal of Experimental Psychology, 67, 1176-1190. doi:https://doi.org/10.1080/17470218.2013.850521

Vigliocco, G., Kousta, S. T., Della Rosa, P. A., Vinson, D. P., Tettamanti, M., Devlin, J. T., \& Cappa, S. F. (2014). The neural representation of abstract words: The role of emotion. Cerebral Cortex, 24, 1767 1777. doi:https://doi.org/10.1093/cercor/bht025

Publisher's note Springer Nature remains neutral with regard to jurisdictional claims in published maps and institutional affiliations. 